\title{
Liquefaction Potential Assessment of Guwahati City Using One Dimensional Ground Response Analysis
}

\author{
Amar Farooq Siddique, Binu Sharma \\ Department of Civil Engineering, Assam Engineering College, Guwahati, India \\ Email: amaribnesiddiq98@gmail.com, binusharma78@gmail.com
}

How to cite this paper: Siddique, A. F., \& Sharma, B. (2020). Liquefaction Potential Assessment of Guwahati City Using One Dimensional Ground Response Analysis. Journal of Geoscience and Environment Protection, 8, 176-194.

https://doi.org/10.4236/gep.2020.85011

Received: April 15, 2020

Accepted: May 18, 2020

Published: May 21, 2020

Copyright $\odot 2020$ by author(s) and Scientific Research Publishing Inc. This work is licensed under the Creative Commons Attribution International License (CC BY 4.0).

http://creativecommons.org/licenses/by/4.0/

\begin{abstract}
Guwahati city which lies in the North Eastern region of India, falls in the highest seismic risk zonal level i.e. zone $\mathrm{V}$ in India. However, there are very few works on seismic hazard analysis of Guwahati soil considering the local site effects. The effect of large modifications in seismic waves that occur due to variation in soil properties near the surface of the earth is of great importance in geotechnical earthquake engineering. Seismic soil liquefaction, a soil seismic hazard, is evaluated in Guwahati city in terms of factor of safety against liquefaction along the soil profiles using ground response analysis. One dimensional ground response analysis has been conducted using equivalent linear and non linear method using the Deepsoil software. The input motion of 2011 Sikkim earthquake $\left(\mathrm{M}_{\mathrm{w}}=6.9\right)$ having bedrock PGA of $0.152 \mathrm{~g}$ at $30 \mathrm{~m}$ depth is considered. A comparative study has been made of the equivalent linear and non linear analysis in terms of surface PGA (g), maximum strain (\%), maximum stress ratio and liquefaction potential using soil profiles of Guwahati city. It has been observed that stiffer soil layer results in similar PGA from both the analysis however non linear analysis generally gives a lesser surface PGA than by equivalent linear analysis. Non linear analysis generally gives a higher strain range and a lower maximum stress ratio as compared to the equivalent linear method. A slightly higher factor of safety is obtained using non linear analysis than using equivalent linear analysis. A soil database of 200 bore holes was used for the study. Spatial distribution of soil liquefaction potential is presented in the form of GIS based maps of factor of safety values.
\end{abstract}

\section{Keywords}

Ground Response Analysis, Equivalent Linear Method, Non Linear Method, Soil Liquefaction 


\section{Introduction}

Liquefaction of soil and its associated damages have been widely observed in many previous earthquakes in the North Eastern region of Assam. The entire North Eastern region of India has witnessed many high magnitude earthquakes in the past decades. The 1897 Great Assam Earthquake of 8.7 moment magnitude, epicentered at the Chedrang Valley Fault and the 1950 Assam earthquake, epicentered near Rima, Tibet of moment magnitude 8.7 Chedrang Valley Fault and the 1950 Assam earthquake, epicentered near Rima, Tibet of moment magnitude 8.7 resulted in severe structural damages as well as large scale soil liquefaction in and around the region. Major earthquakes in India had occurred in the Himalayan Frontal Arc (HFA), extending from Kashmir in the west to Assam in the east. It is one of the most seismically active regions in the world. It constitutes the central part of the Alpine seismic belt. Hence, it is necessary to understand the ground response of the region when subjected to seismic motion. Guwahati, the major city in the north eastern region of India, is growing rapidly with major infrastructures like oil refineries, industries, hospitals, flyovers, multiplex halls, etc. A major earthquake in this region will lead to extensive damage to life and property.

Alluvial deposits with layers of both coarse and fine grained soils are found in this region. Hence, large modifications in earthquake waves can occur due to change in variation in soil properties near to the surface of earth. The amplification of clayey sites is about 1.5 times higher than the rocky and sandy sites (Boominathan et al., 2008). Thus, it is important to consider the effect of local geology and local soil conditions in seismic hazard analysis for the design of structures. The local site effects play an important role in the amplification of bedrock acceleration. Hence the thrust in the present work is to evaluate the ground response together with the liquefaction potential of Guwahati city considering the response of the soil deposit to the motion of the bedrock immediately beneath it due to seismic waves. This paper reports the outcome of one dimensional ground response analysis (GRA) for 200 borehole locations in Guwahati city. Analyses have been conducted using equivalent linear (frequency domain) and non-linear (time domain) approaches using the input motion of 2011 Sikkim earthquake $\left(\mathrm{M}_{\mathrm{w}}=6.9\right)$ having bedrock PGA of $0.152 \mathrm{~g}$.

The liquefaction potential of Guwahati soil has been determined in the past by different research workers (Sharma \& Hazarika, 2013; Raghukanth \& Dash, 2009; Ayothiraman et al., 2012; Sharma \& Chetia, 2015). However, there are very few works on liquefaction potential of Guwahati soil considering the local site effects. The ground motion and liquefaction potential of Guwahati city for an earthquake moment magnitude, $\mathrm{M}_{\mathrm{w}}$ of 8.1 that occurred in the Shillong Plateau was estimated considering the bedrock PGA as $0.19 \mathrm{~g}$ (Raghukanth et al., 2008). The author evaluated the liquefaction potential using the semi empirical equations developed by (Idriss \& Boulanger, 2004). Raghukanth \& Dash (2009) estimated the liquefaction potential of Guwahati city by determining the rock level 
peak ground acceleration (PGA) using finite fault seismological model of (Motazedian \& Atkinson, 2005) and the model was implemented in the time domain through attenuation relations suggested by (Boore, 1983). They took the 1869 Cachar earthquake $(\mathrm{Mw}=7.6), 1897$ great Assam earthquake $(\mathrm{Mw}=8.7)$ and a probable future earthquake in Assam gap $(\mathrm{Mw}=8.5)$. The above authors do not consider the response of the soil i.e. when a motion is travelling from source to the ground surface it would amplify or de-amplify. Researchers showed that the amplification of motion in clay soil is more than in sandy soil. Thus for a better understanding the vulnerability of soil layers, liquefiable strata are determined by using ground response analysis.

\section{Geology of the Study Area}

Guwahati city and its surrounding area consist of the Precambrian Gneissic basement intruded by Porphytic Granites. The Precambrian Gneissic basement is composed of Granite Gneiss, Biotite Schist and Quartzite. This granitic basement is overlain by layers of varying thickness of unconsolidated sand, silt and clay. The city mostly consists of alluvial plain in the central and western part and the hilly region in the south. These hills are mostly Denudational hills consisting of Granite, Gneissic rocks. Rich aquifer system is present in the thick and extensive alluvial deposit and it covers major part of the city.

\section{Evaluation of Ground Response by Frequency Domain One Dimensional Equivalent-Linear Analysis}

In one dimensional GRA it is assumed that the soil is assumed to have the shearing characteristics of a Kelvin-Voigt solid with a linear shear modulus and viscous damping (Kramer, 1996). The stress-strain relationship for such a solid in shear is given by (Kramer, 1996) in Equation (1):

$$
\tau=G \gamma+\eta \frac{\partial \gamma}{\partial t}
$$

where, $\tau=$ shear stress, $G=$ shear modulus, $\eta=$ coefficient of viscous damping parameter and $\gamma=$ shear strain.

The equation of motion for a vertically propagating (in $z$-direction) shear waves is given in Equation (2):

$$
\rho \frac{\partial^{2} u}{\partial t^{2}}=\frac{\partial \tau}{\partial z}
$$

where, $\rho=$ density of medium and $u=$ displacement along lateral direction.

Then the wave equation can be obtained by substituting Equation (1) into Equation (2), which is written as Equation (3),

$$
\rho \frac{\partial^{2} u}{\partial t^{2}}=G \frac{\partial^{2} u}{\partial z^{2}}+\eta \frac{\partial^{3} u}{\partial z^{2} \partial t}
$$

The solution of the above equation yields the one dimensional ground response. The iterative procedure of equivalent-linear analysis requires initial es- 
timates of shear modulus, $G$ and damping ratio, $\xi$ for each layer correspond to the same strain level. The estimated $G$ and $\xi$ are used to compute the ground response, including time histories of shear strain for each layer. The effective shear strain in each layer is then determined from the maximum shear strain in the computed shear strain time history. This computed effective shear strain is used to estimate the corresponding strain compatible shear modulus and damping based on iterative technique. This process is repeated until it gives a convergent solution. Throughout each iteration of the analysis, the soil layer is considered as a linear visco-elastic material, in which constant shear moduli and damping are used.

The material curve proposed by (Seed \& Idriss, 1970) for sandy soil and (Vucetic \& Dobry, 1991) for clay are used. The main input parameter to define modulus reduction curve for sands is effective vertical stress however an addition of plasticity index is needed with vertical effective stress for defining modulus reduction and damping curves for clays.

\section{Evaluation of Ground Response by One Dimensional Nonlinear Method}

The cyclic behaviour of soil i.e., strain-dependent modulus degradation due to number of loading cycles, residual strain of soil and excess pore pressure generation are not accounted for in the equivalent linear analysis. These are accounted for in the non linear analysis. The stress-strain model developed by (Kondner \& Zelasko, 1963) is used for performing nonlinear GRA incorporating Masing criteria.

According to (Hashash et al., 2016), when the modulus reduction and damping curves for a site is absent, the curves proposed by (Vucetic \& Dobry, 1991) for clay and (Seed \& Idriss, 1970) for sandy soil can be considered. Thus for defining the strain dependent shear modulus and damping ratio for soil layers the curve proposed by (Seed \& Idriss, 1970) for sandy soil and (Vucetic \& Dobry, 1991) for clay are considered, and they are subsequently fitted using MRDF procedure. The advantages of one dimensional ground response analysis are-it is very fast, gives direct solution and it is good for very stiff soil/rock and for very small ground motions.

\section{Results and Discussion}

The liquefaction potential is evaluated at 200 representative sites in Guwahati city using the borehole records from standard penetration tests. The input parameters such as SPT N values, wet density, ground water depth and fines content required for the liquefaction potential analyses of the soil profiles at different soil sites in the city, are obtained from the SPT borehole data of 200 bore holes upto 30 meter depth covering an area of $262 \mathrm{~km}^{2}$ in Guwahati city. Rock strata are not encountered upto $30 \mathrm{~m}$ in the 200 bore holes.

To determine the response of the soil to seismic motion, one dimensional 
equivalent linear (EL) and non linear (NL) ground response analysis were carried out using Deepsoil software. For this purpose, an input motion data is required which can be obtained from the seismograph stations. The input motion of 2011 Sikkim earthquake $\left(M_{w}=6.9\right)$ having bedrock PGA of $0.152 \mathrm{~g}$ at $30 \mathrm{~m}$ depth has been used for the purpose. The data is recorded in the Gangtok station which is a rocky site (site class $\mathrm{A}$; density $=25 \mathrm{kN} / \mathrm{m}^{3}$ and shear wave velocity= $1500 \mathrm{~m} / \mathrm{s}$ ) having epicentral distance of $68 \mathrm{~km}$. The shear wave velocity, $V_{s}$ of the boreholes at each depth which is needed for determining the GRA, is calculated using the Equation (4) from (Sharma \& Rahman, 2016).

$$
V_{S}=74.639 * N^{0.3876}
$$

where $N=$ measured SPT value.

Using the bedrock PGA of $0.152 \mathrm{~g}$ at $30 \mathrm{~m}$ depth of the Sikkim earthquake, the PGA at different depths, the strain and maximum stress ratio distribution over depth were obtained for all boreholes. For the analysis the 200 boreholes (BH) of Guwahati city was divided into 26 sites as shown in Table 1. Each site consisted of 5 to 10 bore holes in a locality.

\subsection{Evaluation of Ground Response Analysis}

It has been observed that the bedrock PGA of the input motion gets amplified at ground surface. The range of surface PGA and the range of amplification factors of 26 sites comprising the 200 bore holes for one dimensional EL and NL analysis are shown in Table 1. The surface PGA has been found to be in the range of $0.15 \mathrm{~g}-0.64 \mathrm{~g}$ with amplification factor of $1.00-4.21$ according to the one dimensional EL analysis of Guwahati city. The difference in surface PGA is observed due to the difference in the soil profile of different boreholes. The soil layers consisting of clay displayed amplification of PGA of about 1.5 to 1.8 times higher than sandy layer. This is in agreement with (Boominathan et al., 2008). Figure 1 and Figure 2 show the PGA profile with depth of boreholes for Bhangagarh and Panjabari site respectively according to the one dimensional EL analyses. Figure 3 shows how amplification factor changes with depth for Bhangagarh area.

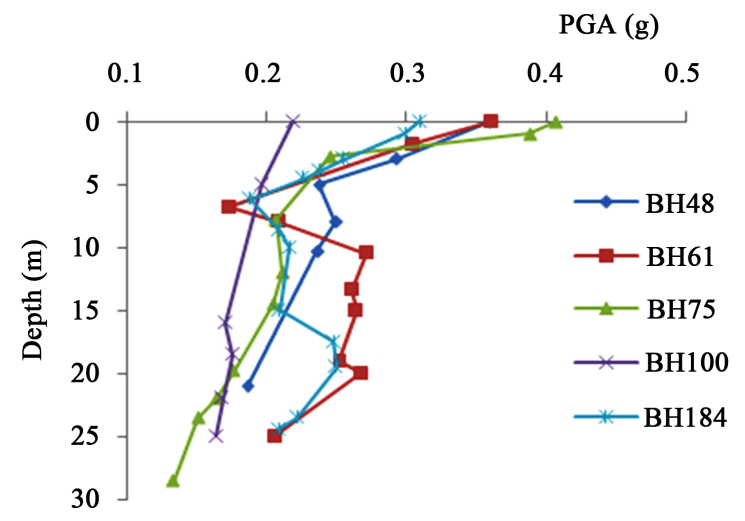

Figure 1. PGA profile of Bhangagarh area (EL method). 


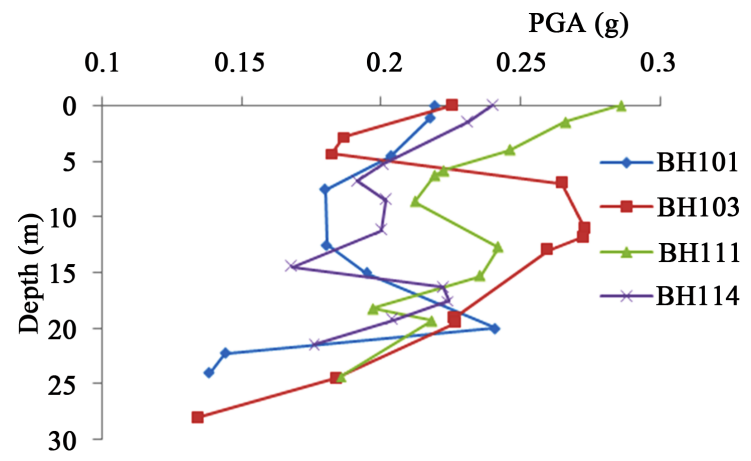

Figure 2. PGA profile of Panjabari area (EL method).

Table 1. Surface PGA and amplification factor of all the sites of Guwahati city.

\begin{tabular}{|c|c|c|c|c|}
\hline \multirow{2}{*}{ Location } & \multicolumn{2}{|c|}{ Surface PGA (g) } & \multicolumn{2}{|c|}{ Amplification Factor } \\
\hline & $\mathrm{EL}$ & NL & $\mathrm{EL}$ & NL \\
\hline AEC Campus & $0.31-0.43$ & $0.22-0.35$ & $2.04-2.83$ & $1.45-2.30$ \\
\hline Amingaon & $0.25-0.36$ & $0.26-0.44$ & $1.64-2.37$ & $1.71-2.89$ \\
\hline Beltola & $0.15-0.35$ & $0.23-0.31$ & $1.00-2.30$ & $1.51-2.04$ \\
\hline Bhangagarh & $0.22-0.41$ & $0.20-0.35$ & $1.45-2.70$ & $1.32-2.30$ \\
\hline Bharalumukh & $0.32-0.60$ & $0.26-0.41$ & $2.11-3.95$ & $1.71-2.70$ \\
\hline Dharapur & $0.16-0.39$ & $0.21-0.32$ & $1.05-2.57$ & $1.38-2.11$ \\
\hline Garchuk & $0.17-0.43$ & $0.26-0.45$ & $1.12-2.83$ & $1.71-2.96$ \\
\hline Hatigaon & $0.19-0.38$ & $0.19-0.35$ & $1.25-2.50$ & $1.25-2.30$ \\
\hline IIT Campus & $0.26-0.43$ & $0.25-0.37$ & $1.71-2.83$ & $1.64-2.43$ \\
\hline Jalukbari & $0.27-0.56$ & $0.20-0.33$ & $1.78-3.68$ & $1.32-2.17$ \\
\hline Kahilipara & $0.31-0.42$ & $0.26-0.39$ & $2.04-2.76$ & $1.71-2.57$ \\
\hline Khanapara & $0.23-0.41$ & $0.21-0.34$ & $1.51-2.70$ & $1.38-2.24$ \\
\hline Lachit Nagar & $0.21-0.56$ & $0.16-0.39$ & $1.38-3.68$ & $1.05-2.57$ \\
\hline Lal Ganesh & $0.29-0.49$ & $0.27-0.39$ & $1.91-3.22$ & $1.78-2.57$ \\
\hline Machkhowa & $0.24-0.34$ & $0.24-0.30$ & $1.58-2.24$ & $1.58-1.97$ \\
\hline Maligaon & $0.28-0.60$ & $0.24-0.42$ & $1.84-3.95$ & $1.58-2.76$ \\
\hline Noonmati & $0.23-0.49$ & $0.22-0.37$ & $1.51-3.22$ & $1.45-2.43$ \\
\hline North Ghy-1 & $0.22-0.37$ & $0.24-0.34$ & $1.45-2.43$ & $1.58-2.24$ \\
\hline North Ghy-2 & $0.27-0.44$ & $0.26-0.33$ & $1.78-2.89$ & $1.71-2.17$ \\
\hline Panbazar & $0.30-0.53$ & $0.26-0.43$ & $1.97-3.49$ & $1.71-2.83$ \\
\hline Panjabari & $0.22-0.29$ & $0.18-0.29$ & $1.45-1.91$ & $1.18-1.91$ \\
\hline Rehabari & $0.31-0.62$ & $0.24-0.53$ & $2.04-4.08$ & $1.58-3.49$ \\
\hline RGB Road & $0.29-0.37$ & $0.25-0.30$ & $1.91-2.43$ & $1.64-1.97$ \\
\hline Silpukhuri & $0.18-0.41$ & $0.19-0.37$ & $1.18-2.70$ & $1.25-2.43$ \\
\hline Six mile & $0.36-0.44$ & $0.26-0.39$ & $2.37-2.89$ & $1.71-2.57$ \\
\hline VIP \& Rani & $0.26-0.64$ & $0.25-0.40$ & $1.71-4.21$ & $1.64-2.63$ \\
\hline
\end{tabular}




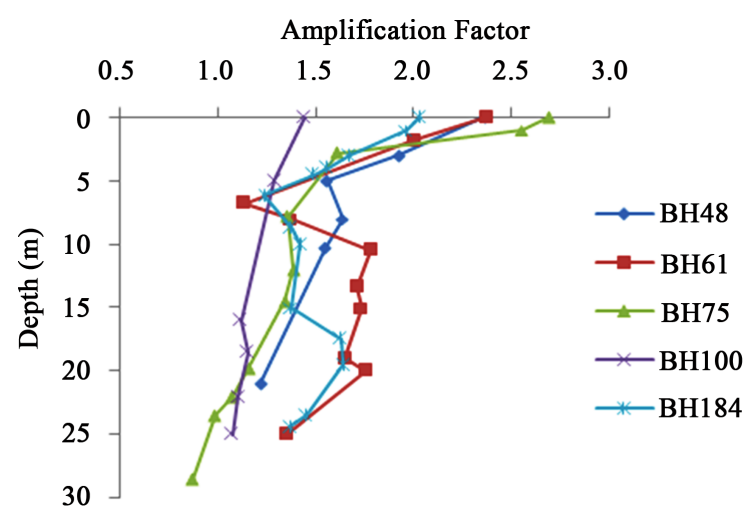

Figure 3. Amplification factor of Bhangagarh area (EL method).

According to the one dimensional NL analysis, the surface PGA is found to be in the range of $0.16 \mathrm{~g}$ to $0.53 \mathrm{~g}$ with amplification factor in the range of 1.05 to 3.49. The maximum surface PGA range of $0.24 \mathrm{~g}$ (B. H. 181) - $0.53 \mathrm{~g}$ (B. H. 166) is obtained at Rehabari site. High amplification of PGA is obtained at B.H. 166 because the soil profile consists of soft clay from $0-3 \mathrm{~m}$ having SPT-N value 0 1 and medium sand from $3-12 \mathrm{~m}$ having SPT-N value $14-15$. The PGA with depth obtained by NL GRA of Rehabari and IIT Campus are presented in Figure 4 and Figure 5.

Figure 6 shows the PGA distribution in soil profile for BH 13 of VIP and Rani area where the PGA at surface level obtained by EL analysis is higher (i.e. $0.64 \mathrm{~g}$ ) than that obtained by NL analysis (i.e. $0.40 \mathrm{~g}$ ). At a depth of approximately $20 \mathrm{~m}$, which constitute a coarse-sandy layer, the PGA obtained by NL analysis and EL analysis are approximately equal (approximately $0.17 \mathrm{~g}$ ) which suggests a stiffer layer in the soil profile which is also evident from SPT-N values. It has been observed that stiffer soil layer results in similar PGA from both the analysis however NL analysis generally gives a lesser surface PGA than by EL analysis. Similar observations are seen in the Assam Engineering college campus and Rehabari area of Guwahati city as shown in Figure 7 and Figure 8. The surface PGA of the 200 boreholes obtained by using EL GRA are presented on a GIS based map in Figure 9 and that obtained by NL GRA are presented on a GIS map in Figure 10.

Figure 11 and Figure 12 show the maximum strain profile with depth for Bhangagarh and Panjabari sites by using one dimensional EL GRA. A wide variation of strain is observed with depth for all the boreholes. It has been observed that less stiffer soil layers having low SPT-N value shows a higher value of strain released. More dissipation of energy is associated with higher strain levels which lead to the softening of the soil with number of loading cycles. Again less dissipation of energy leads to higher amplification of the PGA at various levels of the soil strata. For Bhangagarh area there is a variation of strain of $0.01 \%-0.21 \%$. In Panjabari area, three borehole site show a variation of maximum strain in the range of $0 \%-0.29 \%$, but $\mathrm{BH} 103$ shows the highest value of maximum strain of $0.43 \%$ at depth $9-10 \mathrm{~m}$ due to low SPT-N value and low shear wave velocity. 


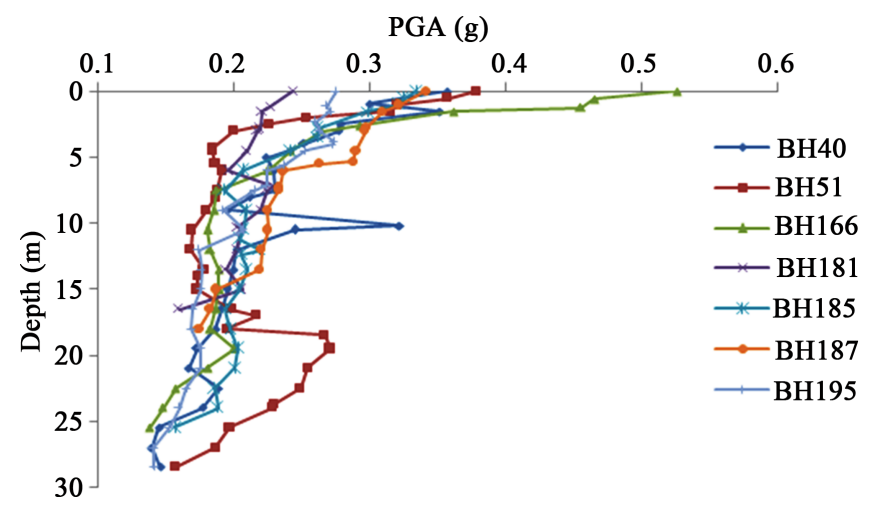

Figure 4. PGA profile at Rehabari area (NL method).

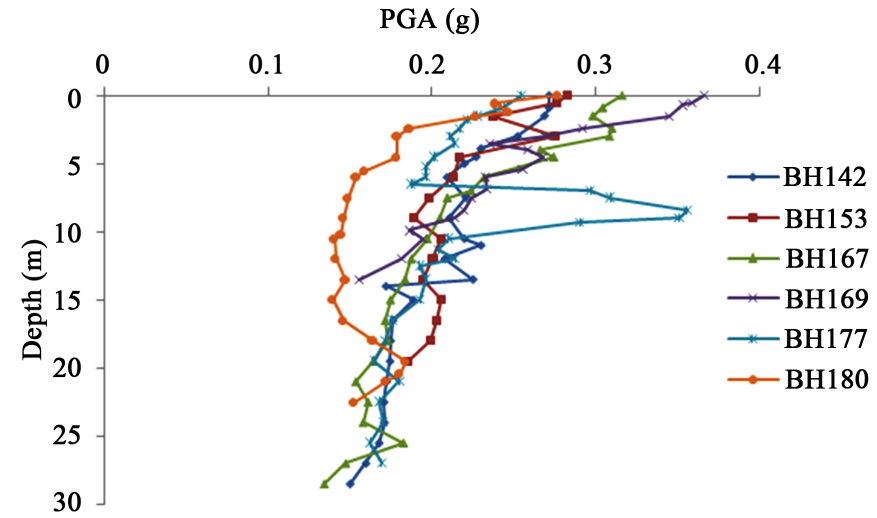

Figure 5. PGA profile at IIT campus (NL method).

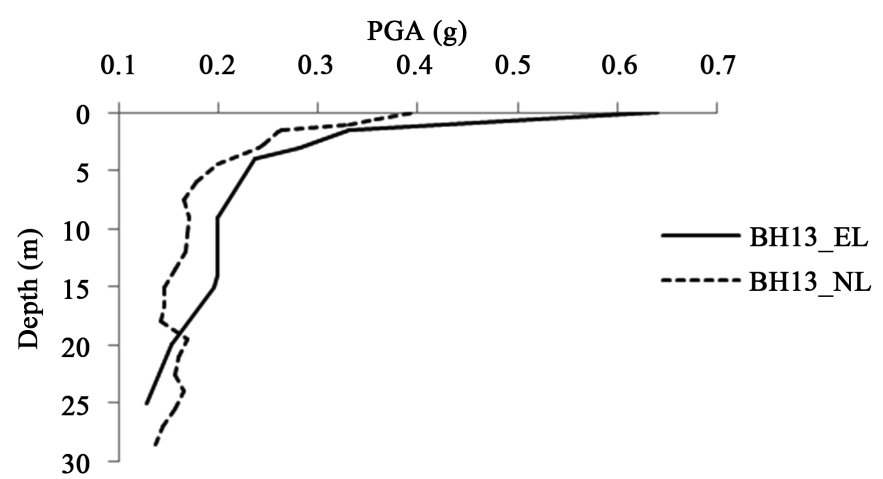

Figure 6. PGA distribution in soil profile for $\mathrm{BH} 13$ of VIP and Rani.

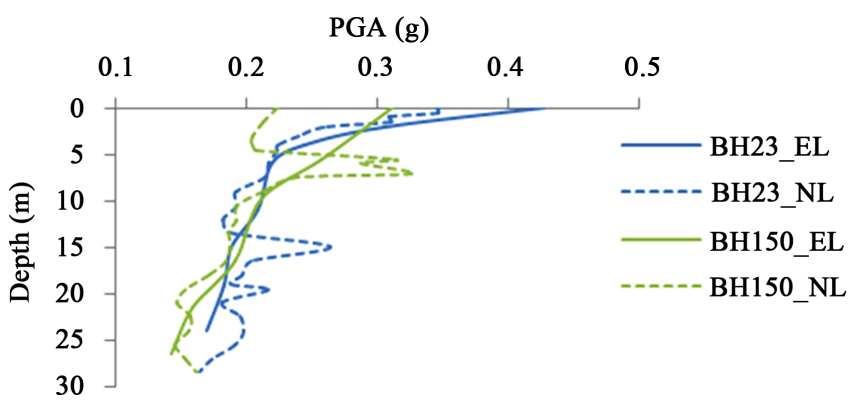

Figure 7. PGA distribution in soil profile for $\mathrm{BH} 23$ \& BH150 of AEC campus. 


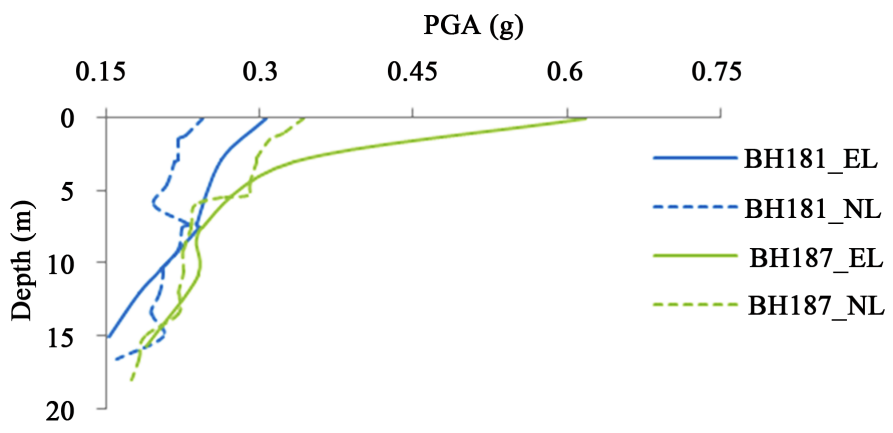

Figure 8. PGA distribution in soil profile for $\mathrm{BH} 181$ \& BH 187 of Rehabari.

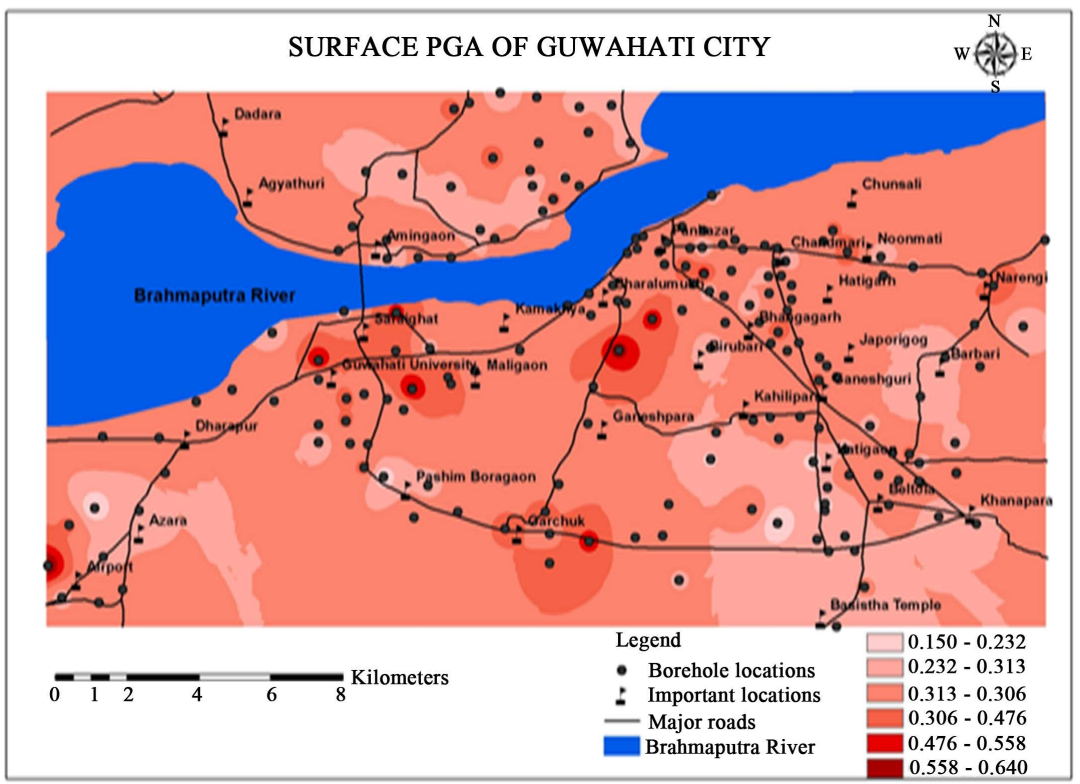

Figure 9. Surface PGA map of Guwahati city by EL method.

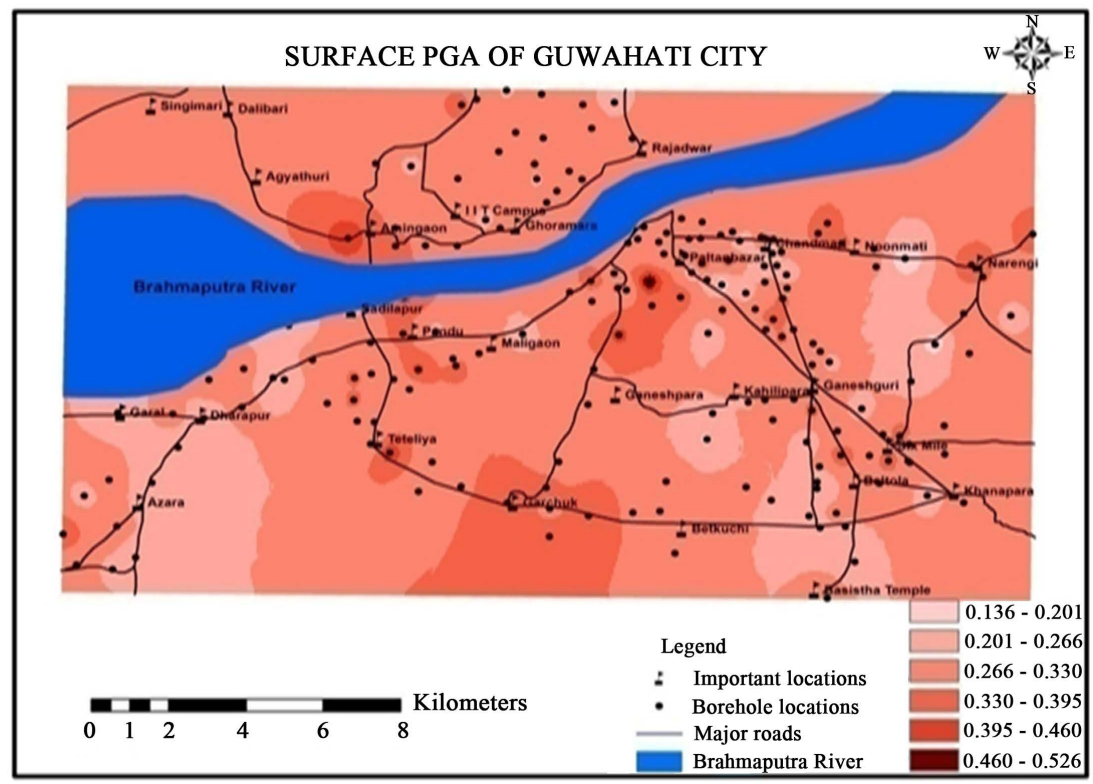

Figure 10. Surface PGA map of Guwahati city by NL method. 


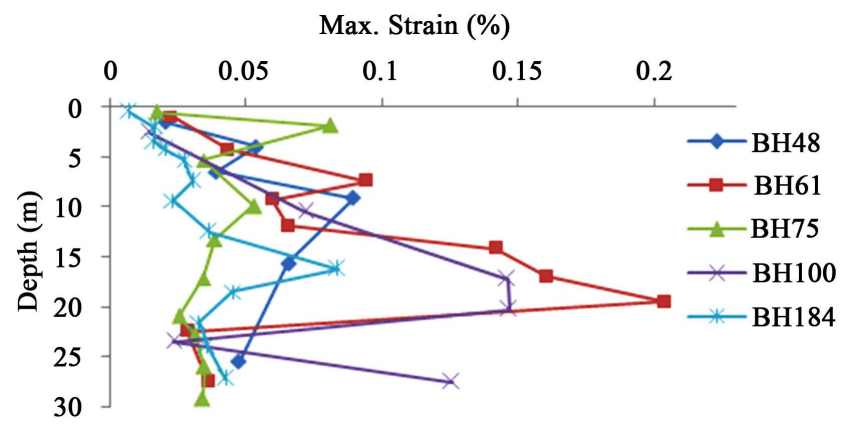

Figure 11. Maximum strain profile of Bhangagarh (EL method).

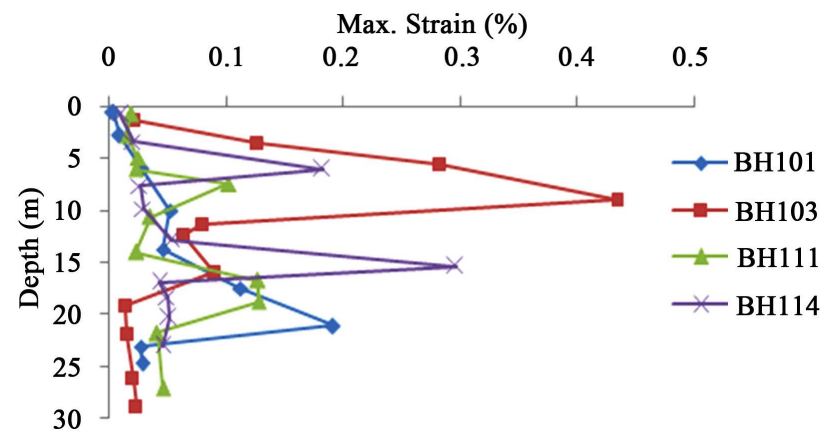

Figure 12. Maximum strain profile of Panjabari (EL method).

The range of maximum strain profile of 200 boreholes sites of Guwahati city has been obtained and shown in Table 2. Lal Ganesh area shows a lowest range of maximum strain of $0.01 \%-0.13 \%$ while Silpukhuri area shows highest range of maximum strain of $0.00 \%-1.58 \%$.

The maximum strains with depth of the 26 sites consisting of the 200 boreholes are also obtained by NL GRA and are shown in Table 2. Figure 13 and Figure 14 show the maximum strain profile with depth for Kahilipara and Garchuk sites by using one dimensional NL GRA. A wide variation of strain is observed with depth for all the boreholes. Lachit Nagar area shows a highest maximum strain range of $0.01 \%-14.40 \%$ however Amingaon area shows lower strain range of $0.00 \%-0.18 \%$. On comparing with EL analysis, it has been observed that NL analysis generally gives a higher maximum strain range. The comparisons of EL analysis with the NL analysis of the maximum strain value with depths of AEC and Rehabari are shown in Figure 15 and Figure 16. The maximum strain range rapidly changes over a small depth in NL analysis however in EL analysis it changes gradually over a large depth.

Next the maximum stress ratio distributions with depth of all the 200 boreholes spreading in 26 sites by both EL and NL analysis are obtained and shown in Table 2. Figure 17 and Figure 18 show the maximum stress ratio with depth of Bhangagarh and Jalukbari sites obtained by EL method respectively, which highlights the effect of local site on different borehole locations corresponding to a single ground motion. Figure 19 and Figure 20 show the maximum stress ratio distributions with depth of Beltola and Sixmile by NL analysis. The maximum 


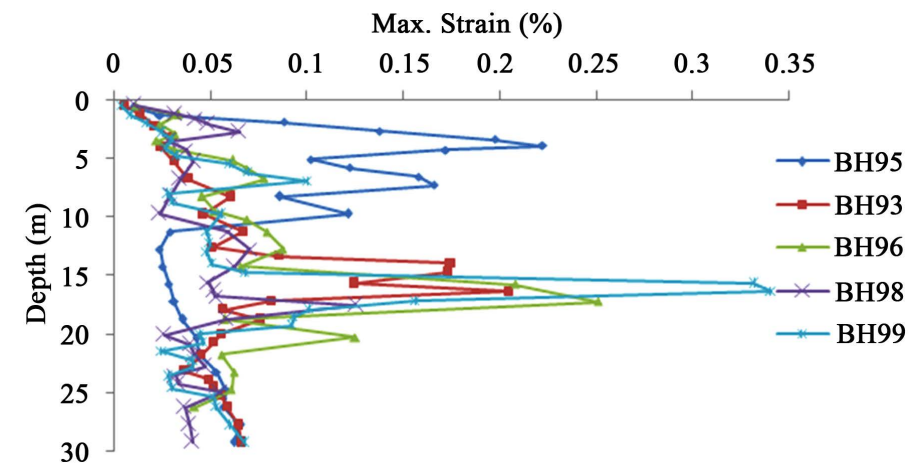

Figure 13. Maximum strain profile of Kahilipara (NL method).

Table 2. Maximum strain and stress ratio of all 200 borehole of Guwahati city.

\begin{tabular}{|c|c|c|c|c|}
\hline \multirow{2}{*}{ Location } & \multicolumn{2}{|c|}{ Maximum Strain (\%) } & \multicolumn{2}{|c|}{ Maximum Stress ratio } \\
\hline & EL & NL & EL & NL \\
\hline AEC Campus & $0.00-0.22$ & $0.00-0.44$ & $0.65-1.22$ & $0.27-0.50$ \\
\hline Amingaon & $0.01-0.20$ & $0.00-0.18$ & $0.63-2.54$ & $0.27-4.81$ \\
\hline Beltola & $0.00-1.10$ & $0.00-11.56$ & $0.33-2.94$ & $0.24-0.53$ \\
\hline Bhangagarh & $0.01-0.21$ & $0.01-7.32$ & $0.47-1.16$ & $0.21-0.35$ \\
\hline Bharalumukh & $0.02-0.20$ & $0.00-6.16$ & $0.64-3.46$ & $0.29-0.40$ \\
\hline Dharapur & $0.00-0.26$ & $0.00-6.61$ & $0.49-2.00$ & $0.22-0.32$ \\
\hline Garchuk & $0.00-0.20$ & $0.00-0.45$ & $0.63-1.16$ & $0.28-1.25$ \\
\hline Hatigaon & $0.01-0.51$ & $0.00-2.22$ & $0.38-1.26$ & $0.19-0.46$ \\
\hline IIT Campus & $0.01-0.54$ & $0.00-3.75$ & $0.69-3.95$ & $0.26-0.37$ \\
\hline Jalukbari & $0.01-0.28$ & $0.00-7.04$ & $0.65-3.87$ & $0.21-0.52$ \\
\hline Kahilipara & $0.01-0.19$ & $0.00-0.33$ & $0.54-2.44$ & $0.26-0.39$ \\
\hline Khanapara & $0.02-0.26$ & $0.00-13.33$ & $0.58-3.22$ & $0.29-1.02$ \\
\hline Lachit Nagar & $0.01-0.47$ & $0.01-14.40$ & $0.41-6.12$ & $0.16-0.39$ \\
\hline Lal Ganesh & $0.01-0.13$ & $0.01-4.37$ & $0.65-1.79$ & $0.53-1.15$ \\
\hline Machkhowa & $0.01-0.25$ & $0.01-0.25$ & $0.31-0.70$ & $0.27-0.55$ \\
\hline Maligaon & $0.00-0.20$ & $0.00-1.23$ & $0.61-5.95$ & $0.25-4.25$ \\
\hline Noonmati & $0.00-0.71$ & $0.00-0.62$ & $0.49-4.51$ & $0.27-3.67$ \\
\hline North Ghy-1 & $0.01-0.58$ & $0.00-0.83$ & $0.45-0.83$ & $0.25-0.66$ \\
\hline North Ghy-2 & $0.00-0.68$ & $0.00-0.81$ & $0.64-1.31$ & $0.26-2.39$ \\
\hline Panbazar & $0.02-0.18$ & $0.00-11.51$ & $0.58-2.83$ & $0.26-0.44$ \\
\hline Panjabari & $0.00-0.43$ & $0.00-12.46$ & $0.51-0.95$ & $0.18-0.74$ \\
\hline Rehabari & $0.01-0.41$ & $0.00-10.85$ & $0.65-5.84$ & $0.24-0.53$ \\
\hline RGB Road & $0.01-0.37$ & $0.00-7.67$ & $0.58-0.88$ & $0.27-2.73$ \\
\hline Silpukhuri & $0.00-1.58$ & $0.01-0.85$ & $0.61-3.70$ & $0.19-0.42$ \\
\hline Six mile & $0.01-0.29$ & $0.00-12.23$ & $0.55-4.00$ & $0.22-0.39$ \\
\hline VIP \& Rani & $0.00-0.20$ & $0.00-0.85$ & $0.57-2.36$ & $0.26-0.40$ \\
\hline
\end{tabular}




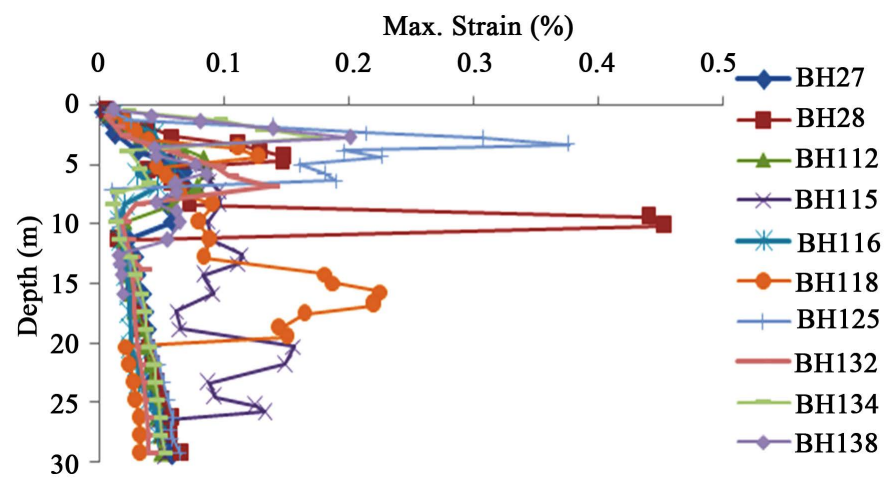

Figure 14. Maximum strain profile of Garchuk (NL method).

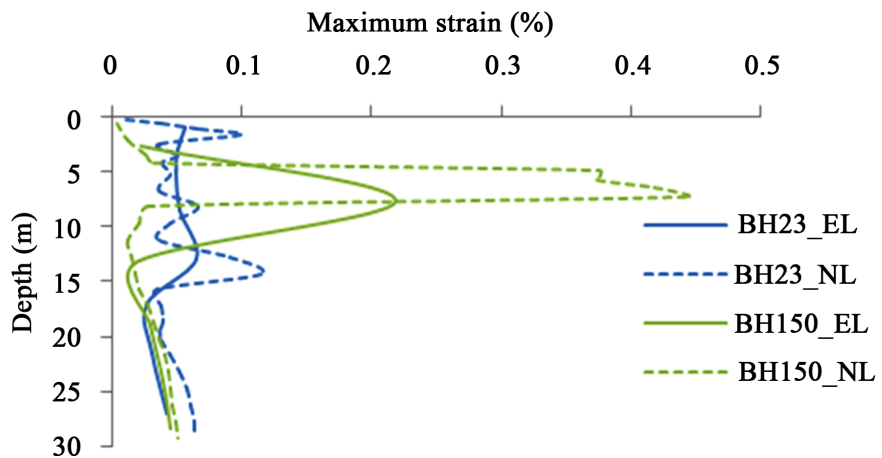

Figure 15. Maximum strain over depth for BH 23 \& BH150 of AEC campus.

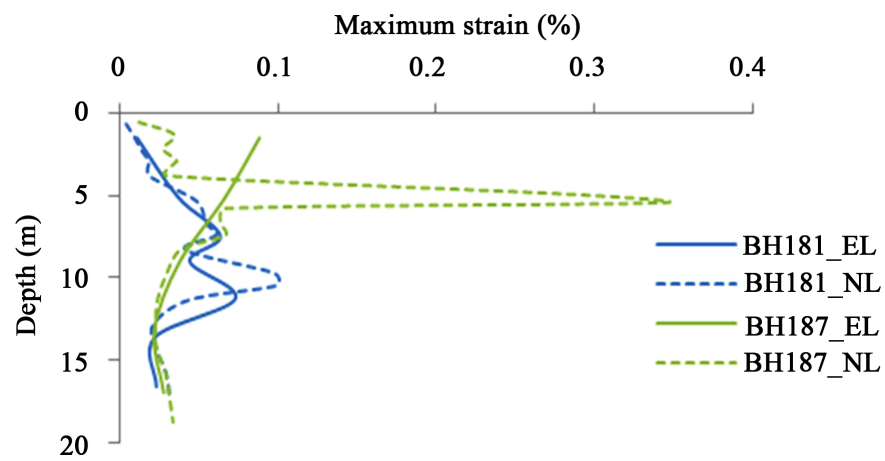

Figure 16. Maximum strain over depth for for BH 181 \& BH187 of Rehabari.

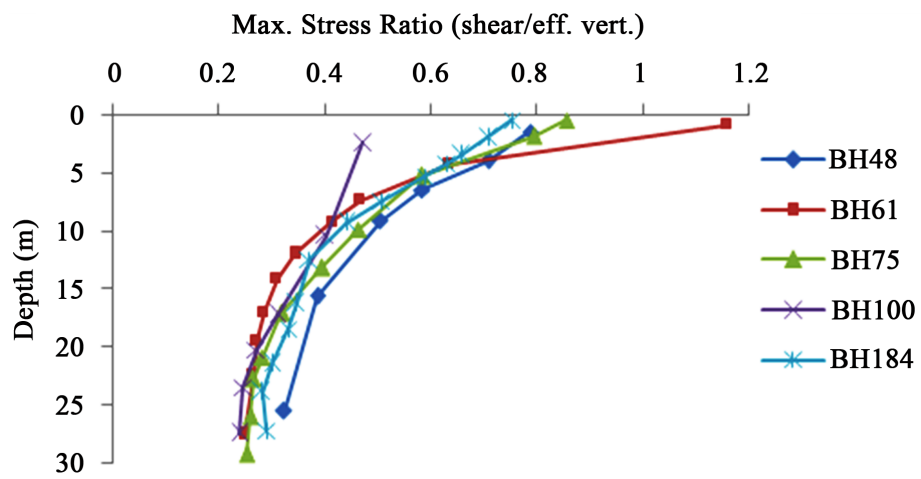

Figure 17. Maximum stress ratio profile of Bhangagarh (EL method). 


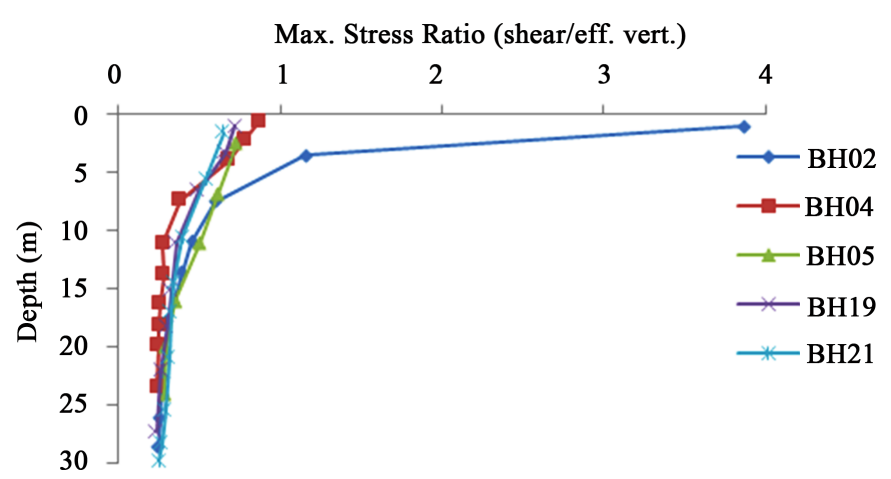

Figure 18. Maximum stress ratio profile of Jalukbari (EL method).

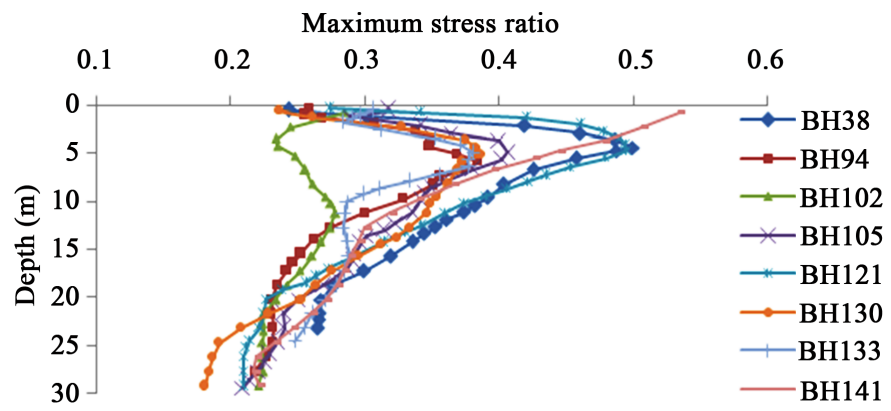

Figure 19. Maximum stress ratio profile of Beltola (NL method).

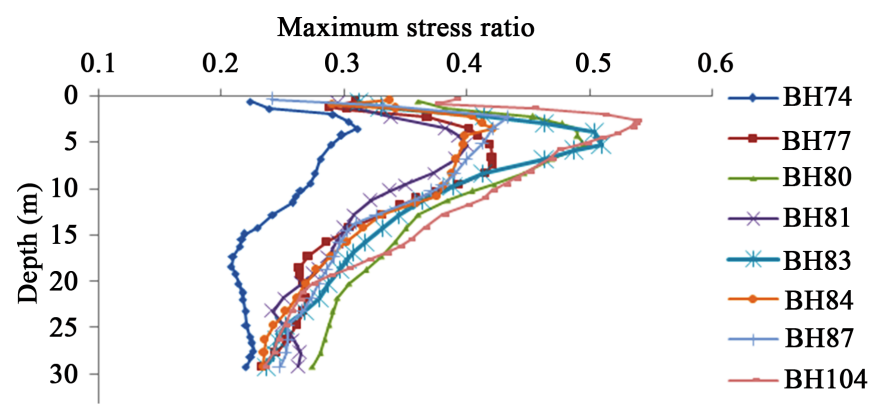

Figure 20. Maximum stress ratio profile of Sixmile (NL method).

stress ratio of Guwahati city has been found to be in the range of $0.31-6.12$ and 0.16 - 4.81 by EL and NL methods respectively. On comparing both the methods it has been found that NL method gives a lower stress ratio range as obtained in Figure 21 (AEC site) and Figure 22 (Rehabari site).

\subsection{Assessment of Liquefaction Potential}

Deterministic assessment of liquefaction potential of 200 boreholes of Guwahati city is also carried out. In this report SPT based deterministic approach of (Youd \& Idriss, 1997) for determining liquefaction resistance of Guwahati city has been adopted. In the deterministic approach the factor of safety with depth against liquefaction potential is determined. According to this analysis liquefaction will occur whenever the factor of safety is less than 1 . However, significant excess pore water pressures can occur even at FOS values greater than 1. Generally, 


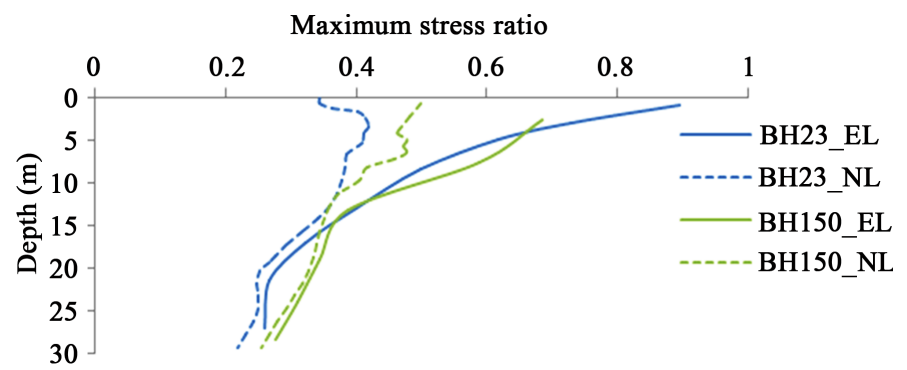

Figure 21. Maximum stress ratio with depth for $\mathrm{BH} 23 \& \mathrm{BH} 150$ of AEC campus.

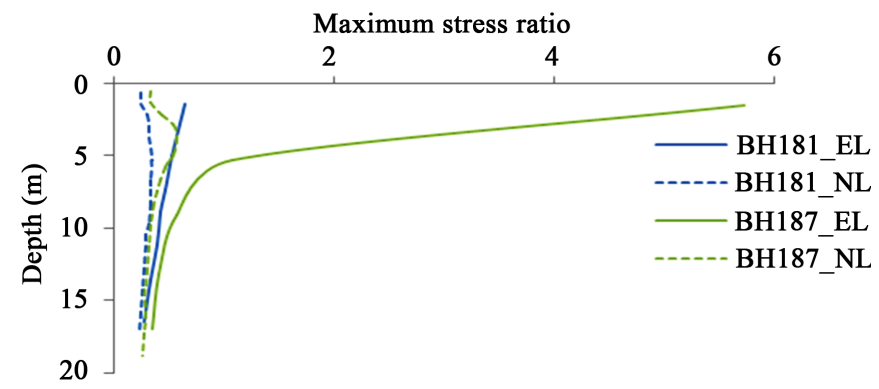

Figure 22. Maximum stress ratio with depth for BH 181 \& BH187 of Rehabari.

the minimum acceptable factor of safety is between 1.25 and 1.50 (Seed et al., 1985).

Evaluation of liquefaction potential requires peak ground acceleration $\left(\mathrm{a}_{\max }\right)$ during earthquake. Peak ground acceleration $\left(a_{\max }\right)$ can be determined from one dimensional ground response analysis (GRA) or from a ground motion relation where it is expressed as a function of magnitude and rupture distance. The liquefaction potential is first determined without using GRA by taking the peak ground acceleration, $\mathrm{a}_{\max }$, for Guwahati city as $0.36 \mathrm{~g}$. This is according to (IS 1893-Part-1, 2002), which puts Guwahati in zone V, a severe seismic zone. Next the liquefaction potential of Guwahati city is determined using GRA. For this purpose the surface PGA values obtained from EL and NL analysis, were used for evaluating the cyclic stress ratio (CSR) as proposed by the (Youd \& Idriss, 1997). The idea is to make a comparative study of the liquefaction potential without ground response and also considering the response of the soil deposit to the motion of the bedrock immediately beneath it due to seismic waves.

Liquefaction during earthquakes has been known to be encountered in deposits consisting of fine to medium sands and sands containing low plasticity below the water table. According to the Chinese criteria, some soils with fines may be susceptible to liquefaction. Fine to medium sands, silty sands and clayey sand that have classification of SP, SW, SC, SM, SP-SC were identified for liquefaction susceptibility. Inorganic silt of classification ML, ML-CL and non plastic inorganic silts were also analyzed for liquefaction susceptibility. 91 boreholes out of the 200 bore holes were identified to have such soil layers. The water table in the 200 boreholes is within 0 to $6 \mathrm{~m}$. In most of the locations in Guwahati city, the water table is at a shallow depth. The water table fluctuation data collected from 
the Central Ground Water Commission for the period 2001-2010 show the water table to rise by about $2 \mathrm{~m}$ during the rainy season and the fall of water level is also about $2 \mathrm{~m}$ in Assam.

Figure 23 and Figure 24 show the results of liquefaction in terms of factor of safety (FOS) against liquefaction with depth for Jalukbari and Dharapur area using GRA (by EL analysis) and without GRA. In Figure 23 it is seen that borehole $(\mathrm{BH})$ 4, 5 and 21 give higher values of FOS and $\mathrm{BH} 2$ give lower values of FOS by considering GRA by EL method as compared to FOS obtained without using GRA. Similarly from Figure 24 FOS values for $\mathrm{BH}$ 6, 7, 8 and 16 are more by using GRA (EL) method as compared to FOS obtained without using GRA. Soil in BH 16 is not susceptible to liquefaction using GRA according to the Sikkim motion earthquake while without GRA by using $\mathrm{a}_{\max }$ as 0.36 from (IS 1893Part 1, 2002), the soil is susceptible to liquefaction.

Out of the 200 borehole sites, $48 \mathrm{BH}$ sites in Guwahati have been found to be susceptible to liquefaction according to the (Youd \& Idriss, 1997) without considering ground response analysis. The rest of the sites where the bore holes are located are not susceptible to liquefaction. Again of the total 200 sites, $67 \mathrm{BH}$ sites are susceptible to liquefaction according to (Youd \& Idriss, 1997) considering GRA (EL). Therefore an additional 19 number of BH sites are susceptible to liquefaction when ground response is considered. This shows the significance of GRA in determining soil liquefaction.

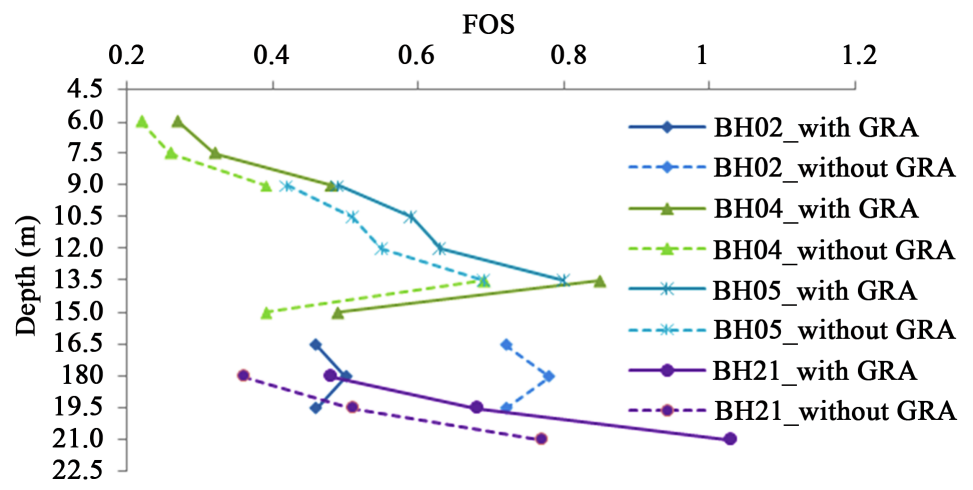

Figure 23. FOS with depth for Jalukbari area.

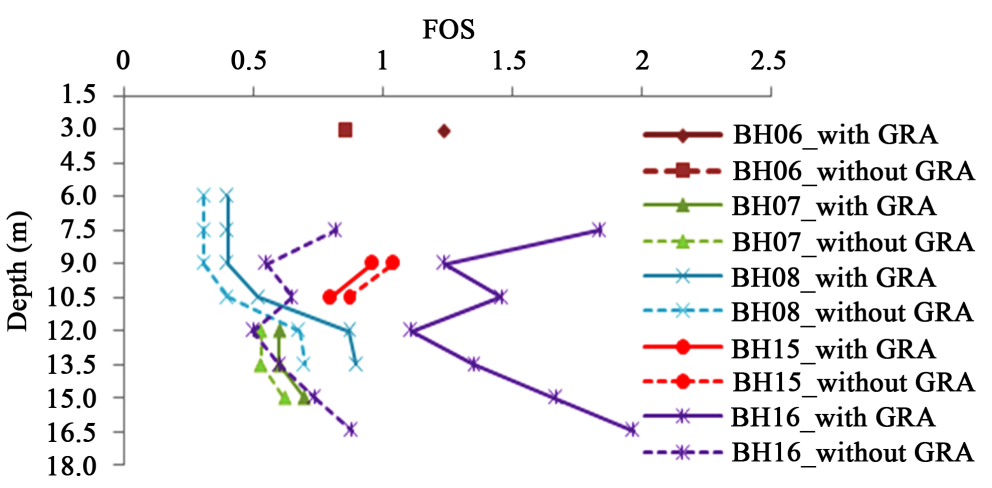

Figure 24. FOS with depth for Dharapur area. 
The FOS with depth using NL GRA has been compared with FOS with depth using EL GRA. Figure 25 and Figure 26 show FOS with depth for Jalukbari and Rehabari area by both EL and NL methods. It has been observed that a slightly higher FOS is obtained using NL GRA than using EL GRA for both the sites. The surface PGA as obtained by NL GRA is less than surface PGA as obtained by EL GRA. This will result in higher values of FOS by NL GRA as compared to EL GRA. The liquefaction potential map of Guwahati city considering GRA by both EL and NL analysis for an earthquake magnitude of 6.9 are shown in Figure 27 and Figure 28 respectively. Out of the total 200 sites, $63 \mathrm{BH}$ sites are susceptible to liquefaction according to (Youd \& Idriss, 1997) considering GRA (NL).

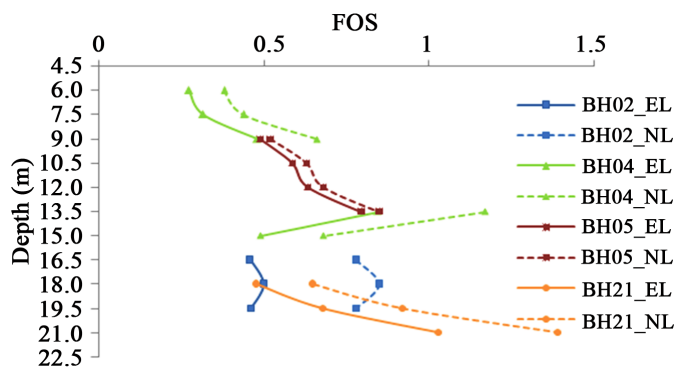

Figure 25. FOS with depth for Jalukbari by EL and NL methods.

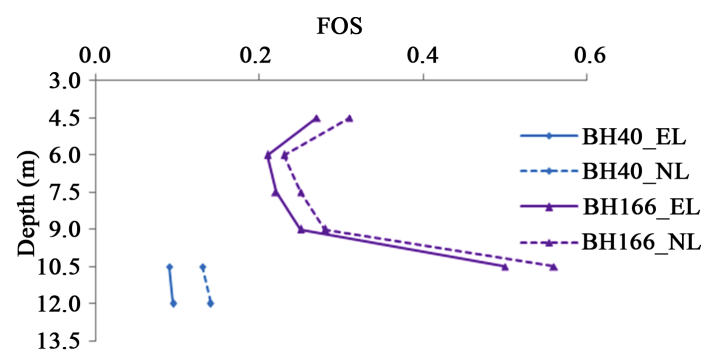

Figure 26. FOS with depth for Rehabari by EL and NL methods.

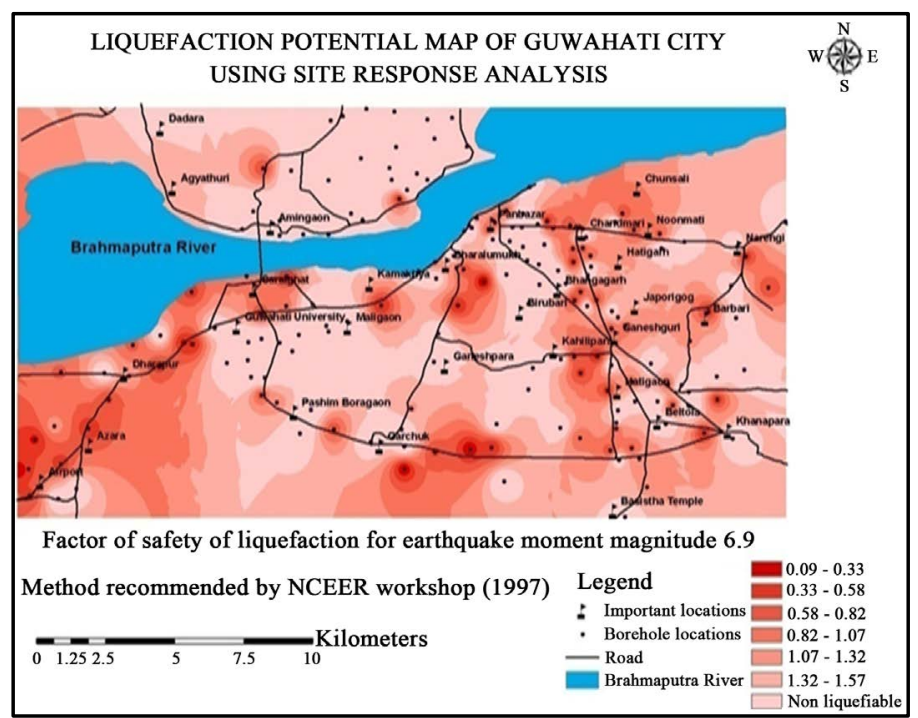

Figure 27. Liquefaction potential map of Guwahati city (PGA from EL method). 


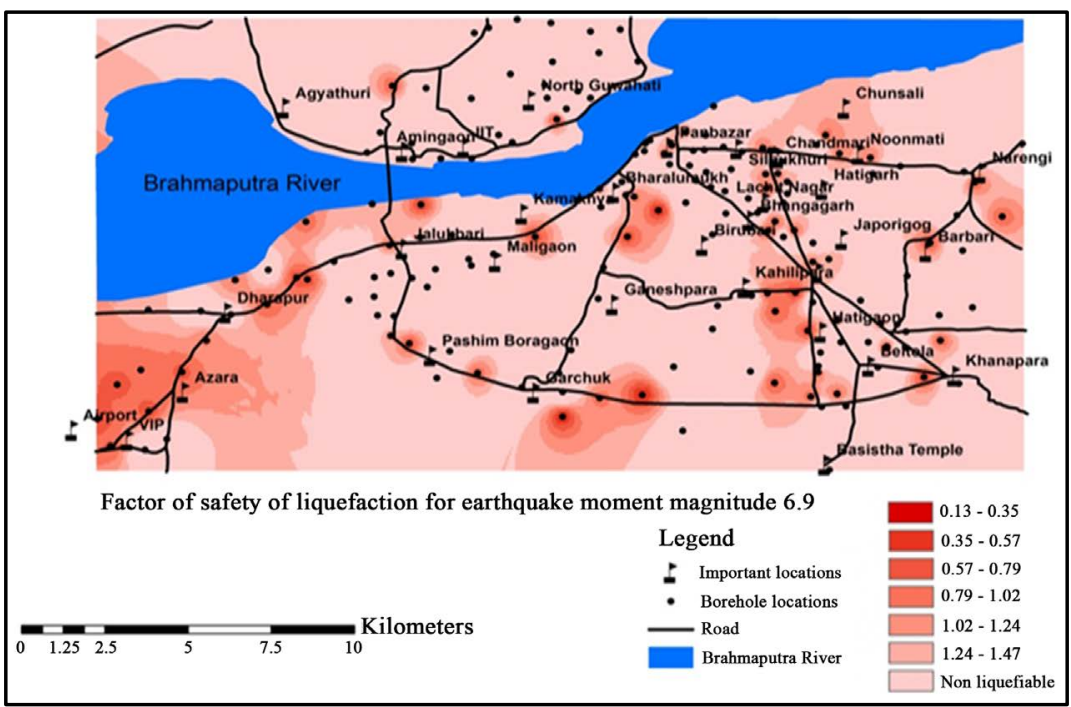

Figure 28. Liquefaction potential map of Guwahati city (PGA from NL method).

The main limitation of one dimensional EL GRA is that the soil layer is considered as a linear visco-elastic material, in which constant shear moduli and damping are used during iteration of the analysis. However the NL GRA uses secant shear moduli due to which it gives a better picture of the soil response.

\section{Conclusion}

The PGA with depth, surface PGA, strain\% and the maximum stress ratio highlights the effect of local site on 200 borehole locations in Guwahati city corresponding to a single ground motion i.e. the 2011 Sikkim earthquake $\left(M_{w}=6.9\right)$ having bedrock PGA of $0.152 \mathrm{~g}$ at $30 \mathrm{~m}$ depth. Both one dimensional equivalent linear and non linear analysis were done for the 200 bore holes extending upto $30 \mathrm{~m}$ depth in Guwahati city. It has been observed that stiffer soil layer results in similar PGA from both the analysis however NL analysis generally gives a lesser surface PGA than by EL analysis. The surface PGA has been found to be in the range of $0.15 \mathrm{~g}-0.64 \mathrm{~g}$ with amplification factor of $1.00-4.21$ according to the one dimensional EL analysis of Guwahati city. According to one dimensional NL analysis, the surface PGA is found to be in the range of $0.16 \mathrm{~g}$ to $0.53 \mathrm{~g}$ with amplification factor in the range of 1.05 to 3.49 . The variation of surface PGA by the linear and non linear approach is not found to be very significant.

A wide variation of strain and maximum stress ratio is observed with depth for all the boreholes. It has been observed that NL analysis generally gives a higher strain range and a lower maximum stress ratio as compared to the EL method.

It has been observed that a slightly higher FOS is obtained using NL GRA than using EL GRA. Again of the total 200 sites, $67 \mathrm{BH}$ sites are susceptible to liquefaction according to (Youd \& Idriss, 1997) considering surface PGA as obtained by EL GRA. Again $63 \mathrm{BH}$ sites are susceptible to liquefaction according to (Youd \& Idriss, 1997) considering NL GRA. 


\section{Conflicts of Interest}

The authors declare no conflicts of interest regarding the publication of this paper.

\section{References}

Ayothiraman, R., Raghukanth, S. T. G., \& Sreelatha, S. (2012). Evaluation of Liquefaction Potential of Guwahati: Gateway City to Northeastern India. Natural Hazards, 63, 449-460. https://doi.org/10.1007/s11069-012-0158-9

Boominathan, A., Dodagoudar, G. R., Suganthi, A., \& Maheswari, U. R. (2008). Seismic Hazard Assessment of Chennai City Considering Local Site Effects. Journal of Earth System Sciences, 117, 853-863. https://doi.org/10.1007/s12040-008-0072-4

Boore, D. M. (1983). Stochastic Simulation of High-Frequency Ground Motions Based on Seismological Models of the Radiated Spectra. Bulletin of the Seismological Society of America, 73, 1865-1894.

Hashash, Y. M. A., Musgrove, M. I., Harmon, J. A., Groholski, D. R., Phillips, C. A., \& Park, D. (2016). DEEPSOIL Version 6.1. User Manual(137 p.).

Idriss, I. M., \& Boulanger, R. W. (2004). Semi-Empirical Procedures for Evaluating Liquefaction Potential during Earthquakes. In 11th International Conference on Soil Dynamics \& Earthquake Engineering (ICSDEE) and the 3rd International Conference on Earthquake Geotechnical Engineering (ICEGE) (pp. 32-56). Singapore: Stallion Press.

IS 1893-Part-1 (2002). Indian Standard Criteria for Earthquake Resistance Design of Structures. New Delhi: BIS.

Kondner, R. L., \& Zelasko, J. S. (1963). A Hyperbolic Stress-Strain Formulation of Sands. In Proceedings of the 2nd Pan American Conference on Soil Mechanics and Foundation Engineering (pp. 289-324). Sao Paulo.

Kramer, S. L. (1996). Geotechnical Earthquake Engineering (p. 653). Upper Saddle River, NJ: Prentice Hall.

Motazedian, D., \& Atkinson, G. M. (2005). Stochastic Finite-Fault Modeling Based on a Dynamic Corner Frequency. Bulletin of the Seismological Society of America, 95, 9951010. https://doi.org/10.1785/0120030207

Raghukanth, S. T. G., \& Dash, S. K. (2009). Evaluation of Seismic Soil-Liquefaction at Guwahati City. Environmental Earth Sciences, 61, 355-368. https://doi.org/10.1007/s12665-009-0347-3

Raghukanth, S. T. G., Sreelatha, S., \& Dash, S. K. (2008). Ground Motion Estimation at Guwahati City for an Mw 8.1 Earthquake in the Shillong Plateau. Tectonophysics, 448, 98-114. https://doi.org/10.1016/j.tecto.2007.11.028

Seed, H. B., \& Idriss, I. M. (1970). Soil Moduli and Damping Factors for Dynamic Response Analyses. Technical Report EERRC-70-10, Berkeley, CA: University of California.

Seed, H. B., Tokimatsu, K., Harder, L. F., \& Chung, R. M. (1985). The Influence of SPT Procedures in Soil Liquefaction Resistance Evaluations. Journal of Geotechnical Engineering, ASCE, 111, 1425-1445. https://doi.org/10.1061/(ASCE)0733-9410(1985)111:12(1425)

Sharma, B., \& Chetia, M. (2015). Deterministic and Probabilistic Liquefaction Potential Evaluation of Guwahati City. In The 15th Asian Regional Conference on Soil Mechanics and Geotechnical Engineering (pp. 823-828). Tokyo: Japanese Geotechnical Society, Special Publication. https://doi.org/10.3208/jgssp.IND-32 
Sharma, B., \& Hazarika, P. J. (2013). Assessment of Liquefaction Potential of Guwahati City: A Case Study. Journal of Geotechnical and Geoenvironmental Engineering, 31, 1437-1452. https://doi.org/10.1007/s10706-013-9667-x

Sharma, B., \& Rahman, S. K. (2016). Use of GIS Based Maps for Preliminary Assessment of Subsoil of Guwahati City. Journal of Geoscience and Environment Protection, 4, 106-116. https://doi.org/10.4236/gep.2016.45011

Vucetic, M., \& Dobry, R. (1991). The Effect of Soil Plasticity on Cyclic Response. ASCE Geotechnical Journal, 117, 89-107.

https://doi.org/10.1061/(ASCE)0733-9410(1991)117:1(89)

Youd, T. L., \& Idriss, I. M. (1997). Proceeding of the NCEER Workshop on Evaluation of Liquefaction Resistance of Soils. Buffalo, NY: National Center for Earthquake Engineering Research, State University of New York at Buffalo. 